\title{
Association of Botryosphaeria Panicle and Shoot Blight of Pistachio with Injuries of Fruit Caused by Hemiptera Insects and Birds
}

Themis J. Michailides and David P. Morgan, Department of Plant Pathology, University of California, Davis, Kearney Agricultural Research and Extension Center, Parlier 93648

\begin{abstract}
Michailides, T. J., and Morgan, D. P. 2016. Association of Botryosphaeria panicle and shoot blight of pistachio with injuries of fruit caused by Hemiptera insects and birds. Plant Dis. 100:1405-1413.

Panicle and shoot blight of pistachio caused by species of Botryosphaeriaceae fungi remains one of the major diseases of pistachio in California, with the highest potential for crop destruction because buds and fruit clusters (panicles) are killed. Pistachio fruit can also be damaged by various insect pests. For instance, hemipteran insects are considered major pests of pistachio and can attack maturing fruit, causing necrotic areas on the fruit epicarp (epicarp lesion). Surveys in pistachio orchards showed a putative association of punctures of pistachio fruit with infection by Botryosphaeriaceae fungi, resulting in panicle and shoot blight. This study was undertaken to determine any association of Botryosphaeriaceae fungi with fruit bearing epicarp lesions and whether hemipteran insects can actively carry propagules of the pathogens to healthy fruit and cause disease. Three large insects of the order Hemiptera (Thyanta pallidovirens, Acrosternum hilare, and Leptoglossus clypealis) were used in pathogen-spread and infection experiments. The most frequently isolated species of the family Botryosphaeriaceae in pistachio, Neofusicoccum mediterraneum, was used in these transmission experiments. Significantly higher incidence of fruit infected by $N$. mediterraneum was recorded when pistachio clusters were sprayed with a spore suspension of $N$. mediterraneum and caged with the above insects than the level of infected fruit sprayed similarly with the pathogen but caged without

any insects. Furthermore, increasing the number of insects caged with pistachio clusters resulted in an increase of insect feeding punctures and, subsequently, disease incidence. Similarly, increasing the number of wounds per fruit made with a needle, simulating injuries caused by the insect's stylet, resulted in significantly higher incidence of infected fruit than for wounded fruit with fewer injured sites. In addition, birdinjured fruit were also associated with higher incidence of panicle blight than fruit not injured by birds, especially in orchards with high disease incidence. In laboratory experiments, wounding or applying fruit sap to nonwounded fruit resulted in significantly higher incidence of infected fruit than in nonwounded fruit without sap. In field experiments, wounding of fruit before or after inoculation with $N$. mediterraneum resulted in higher disease incidence than nonwounded and inoculated fruit. Additionally, fruit sap enhanced initial mycelial growth of $N$. mediterraneum. Protecting fruit clusters from injuries by hemipteran insects or birds using mesh cages significantly reduced the incidence of panicle and shoot blight. The association of wounding by hemipteran insects and birds with high incidence of infected pistachio fruit may explain partially the broad distribution of Botryosphaeria panicle and shoot blight among pistachio orchards of the central San Joaquin Valley, even in areas where inoculum sources are not nearby.
\end{abstract}

Panicle and shoot blight of pistachio (Pistacia vera L.), caused by the pycnidial stage of the ascomycete Neofusicoccum mediterraneum Crous, M. J. Wingf. \& A. J. L. Phillip (formerly identified as Botryosphaeria dothidea Goss \& Dug. de Not.), was first discovered in 1983 and reported in 1984 on pistachio fruit grown in the northern Sacramento Valley (Rice et al. 1985). The pathogen kills fruiting buds, clusters, and fruiting wood, resulting in significant crop losses (Michailides 1991). Disease symptoms include blighting of infected pistachio parts and formation of cankers on shoots, where the organism can survive for at least 6 years (Michailides et al. 1998). The disease kills fruiting buds and panicles and reduces yield. A common avenue for infection is at the panicle, which results in blighting and, eventually, collapse of fruit clusters.

Within 2 years after the first discovery of panicle and shoot blight in the oldest pistachio orchard in Butte County, the disease was then found in orchards in a number of counties in the northern, central, and even southern San Joaquin Valley in California (Michailides 1989). The pseudothecial stages of Botryosphaeriaceae species have been reported on giant sequoia (Sequoiadendron giganteum) and on coastal

Corresponding author: T. J. Michailides; E-mail: tjmichailides@ucanr.edu

*The $\boldsymbol{e}$-Xtra logo stands for "electronic extra" and indicates that one supplementary figure is published online.

Accepted for publication 23 February 2016.

http://dx.doi.org/10.1094/PDIS-09-15-1077-RE

(C) 2016 The American Phytopathological Society redwood (Sequoia sempervirens) in California (Worrall et al. 1986) but only the pycnidial stage was found initially on pistachio and almond (Michailides 1991). In 1995, the anamorphs of Botryosphaeria spp. showing conidia types of $B$. dothidea (i.e., fusiform, hyaline, and mainly aseptate) were reported in more than 50 species that belonged to 13 families of chaparral plants in southern California (Brooks and Ferrin 1994). By 2000, 35 additional plants were reported as new hosts of Botryosphaeriaceae fungi (Michailides and Morgan 2004). In the last decade (2005 to 2015), a plethora of hosts attacked by a number of species belonging in the Botryosphaeriaceae family of fungi were reported as "first reports." In addition to pistachio panicle and shoot blight, reports included other major crops in California such as almond, walnut, avocado, citrus, and olive attacked by Botryosphaeriaceae species (Adesemoye et al. 2014; Chen et al. 2014a; Inderbitzin et al. 2010; McDonald and Eskalen 2011; Moral et al. 2010). Thus far, the pseudothecial stage has not been found on pistachio in California; however, it has been found in avocado, olive, firethorn, blackberry, walnut, and almond (Michailides and Morgan 2010). Based on phylogenetic studies, however, we have only identified the sexual stages of B. dothidea and N. parvum causing branch cankers on almond, olive, and walnut in California (Chen et al. 2014a; Inderbitzin et al. 2010).

Initially, the cause of panicle and shoot blight was reported as B. dothidea based on morphological identification (Michailides 1991). However, after phylogenetic study of 304 isolates of Botryosphaeriaceae fungi causing panicle and shoot blight, eight species were determined. In addition to $N$. mediterraneum, $N$. parvum was the second most frequently encountered and also widespread species (Chen et al. 2014b). Although the sexual stage of $N$. mediterraneum 
has not been found in California pistachio, it has been found and described recently in southern Spain (Moral et al. 2015).

The majority of pistachio orchards in California are adjacent to other crops such as stone fruit, almond, fig, grape, pomegranate, and walnut. Some pistachio orchards are planted next to pastures or riparian areas. These latter pistachio orchards are usually attacked by a number of small hemipteran insects early in the season and by several large hemipteran insect pests later in the season (Michailides et al. 1987). Symptoms that develop on the fruit epicarp because of hemipteran punctures have been described previously (Michailides et al. 1987, 1988; Rice et al. 1985, 1988). Briefly, the punctured fruit develop black discoloration on their epicarp, and may exude sap that dries around the puncture site. The lesions can extend over one or both sides of the pistachio fruit without extending into the fruit peduncle (stem) and the damage is called 'epicarp lesion' (EL). However, in the last decade or so, we have frequently observed that the black discoloration (EL) extended via the fruit peduncle into the main rachis of the panicle, causing a black lesion and suggesting a pathogen involvement as well. Also, after opening the shell of fruit showing EL, mycelia on the inner surface of shell and outer surface of the kernel were evident, suggesting that molds were introduced inside the fruit cavity (shells were still sealed), developed, and in some instances colonized and decayed the kernel.

Insects of the order Hemiptera have been associated with transmission of some plant diseases (Carter 1973; Ershard and Barkordary 1976). In soybean, stinkbug members of the Pentatomidae family were implicated as vectors of the nonfilamentous fungi Eremothycium coryli (= Nematospora coryli) causing a yeast-spot disease (Daugherty 1967); in pistachio, hemipteran insects have been shown to vector the same fungus, causing a slimy decay of the kernel called stigmatomycosis (Ershard and Barkordary 1976). In 1990, Michailides and Morgan reported that large hemipteran insects can transmit E. coryli and Aureobasidium pullulans, causing stigmatomycosis in California pistachio (Michailides and Morgan 1990). Although other orders of insects (e.g., Coleoptera) have been associated with diseases caused by filamentous fungi (Kolařík et al. 2011; Tisserat et al. 2009), hemipteran insects occasionally were associated with fungi (Somonet 1955).

Various birds regularly visit pistachio orchards before and during maturation of fruit and can become a nuisance to the growers and damage yields (Salmon et al. 1986). Birds can rupture the hull, shell, and kernel of pistachio fruit. After birds peck through the hull to eat part of the kernel, fungi can infect the exposed and wounded fruit (Doster and Michailides 1994).

The purpose of this research was to investigate (i) possible associations of hemipteran insects attacking pistachio with panicle and shoot blight disease of pistachio; (ii) transmission of the pathogen to pistachio fruit, resulting in Botryosphaeria panicle and shoot blight; (iii) the effect of simulating wounding by hemipteran insects on disease development; and (iv) any association of bird-damaged fruit with panicle and shoot blight disease. The initial observations on the association of hemipteran insects and birds with panicle and shoot blight of pistachio have been published (Michailides et al. 1997).

\section{Materials and Methods}

Field observations on a putative association of insect-injured pistachio fruit and infection by Neofusicoccum mediterraneum. Because Neofusicoccum mediterraneum is the dominant species occurring in nut crops (pistachio, almond, and walnut) in our conditions (Chen et al. 2014a,b; Inderbitzin et al. 2010), we considered here all the Botryosphaeriaceae isolates with conidia of the B. dothidea type as $N$. mediterraneum.

To determine the incidence of putative fungal pathogens associated with insect-injured fruit, in 3 years $(1996,1997$, and 2000), three samples each of 24 to 135 nonsplit fruit per sample bearing obvious EL (punctures) caused by hemipteran insects were collected from 3 , 5 , and 2 orchards, respectively. The collected fruit were placed in an ice chest, brought to the laboratory, and refrigerated at $4^{\circ} \mathrm{C}$ until examined. For each insect-injured fruit, a nonsplit fruit without any apparent EL symptoms was collected to serve as a noninjured control fruit. Fruit both with and without insect injuries were surface sterilized in $0.1 \%$ sodium hypochlorite solution (commercial bleach, $5.25 \% \mathrm{NaOH}$ solution [ $\mathrm{vol} / \mathrm{vol}]$ ) for $2 \mathrm{~min}$, allowed to dry, cut in half with a sterile knife, and examined with a dissecting microscope $(\times 10$ to 20) for any presence of mycelium in the inner surface of shells or on the young embryo. When mycelia were present, isolations were made by transferring a small amount of mycelia aseptically with tweezers to a 9 -cm-diameter petri plate containing acidified $(25 \%$ [ $\mathrm{vol} / \mathrm{vol}$ ] lactic acid $2.5 \mathrm{ml} /$ liter) potato dextrose agar (APDA), to identify the fungal species involved. In the case of noninjured control fruit, isolations were made by plating small pieces ( 2 to 3 by 2 to $3 \mathrm{~mm}$ ) of internal shell tissues or embryo to recover any fungal propagules present. One plate with three mycelial pieces or shell fragments covered with mycelia internally per fruit was used, the plates with transferred mycelia or fruit tissues were incubated at $30^{\circ} \mathrm{C}$ for 5 to 7 days, and the fungi developed were identified.

Isolation of $\mathrm{N}$. mediterraneum from insects and insect parts. To determine whether $N$. mediterraneum pycnidiospores were found in association with hemipteran insects, 100 and 117 Leptoglossus clypealis Hiedemann (leaffooted bug [LFB]; family Pentatomidae) and 11 and 34 Thyanta pallidovirens Stål (green stinkbug; family Coreidae) (Supplementary Fig. S1) were collected from an orchard in Sacramento County where Botryosphaeria panicle and shoot blight was severe during September to October in year 1 (2003) and year 2 (2004) of this study, respectively. Many of the insects were collected individually in paper bags $(10.5$ by $20 \mathrm{~cm})$ early in the morning from harvest bins as the insects crawled on top of the harvested fruit, because they aggregated within the shriveled and blighted leaves at the tip of blighted shoots killed by the pathogen. The insects were brought to the laboratory in an ice chest and killed by freezing overnight at $-16^{\circ} \mathrm{C}$. After freezing, 80 L. clypealis insects were plated (3 insects per plate) on APDA and the plates were incubated at $27^{\circ} \mathrm{C}$ for 9 days when the developed colonies from the plated insects were recorded.

In a second experiment, using insects that were collected from other orchards, only the stylets (proboscis) were removed aseptically from 88 killed LFB and plated in 11 petri plates ( 8 stylets per plate) containing APDA. In a third experiment, 61 killed LFB were placed in $100 \mathrm{ml}$ of water and shaken vigorously for $2 \mathrm{~h}$ in a reciprocal shaker, and $0.2 \mathrm{ml}$ of the washings were plated in each of 10 APDA plates. All the plated insects were incubated at $27^{\circ} \mathrm{C}$ for 9 days, and fungi that developed from the insects, stylets, and insect washings were recorded. In a fourth experiment, legs and excretions from LFB were placed on a sterilized microscope slide and examined with a compound microscope for the presence of $N$. mediterraneum pycnidiospores. The shape and size of the pycnidiospores of species of Botryosphaeriaceae are very distinct from and larger than those of other fungi and it was easy to distinguish them among the various parts of excretions. When present in insect excretions, the excretions were spread on water agar (WA) plates and the putative Botryosphaeriaceae spores were picked up with a fine flattened transfer needle and plated on APDA plates; germination of these spores was recorded $8 \mathrm{~h}$ later and colony identification was made after 3 days of incubation of the plates at $27^{\circ} \mathrm{C}$. These experiments were repeated in year 2 of the study.

Disease transmission by hemipteran insects. Adults of three hemipteran insect species collected from pistachio orchards were reared in the laboratory for several generations by feeding them on pesticidefree green bean (Phaseolus vulgaris) (Wheeler 2001). Adults of these hemipterans from the clean colonies were used in transmission experiments. The species used were the stinkbug, LFB, and Acrosternum hilare Say (family Coreidae). These three large insect species are active feeders of pistachio fruit and cause EL by puncturing the epicarp (Michailides et al. 1987, 1988; Rice et al. 1985). Later in the season, these insects switch from feeding on the hull to the kernel, causing kernel necrosis (Michailides 1989; Rice et al. 1986). Pistachio fruit clusters on trees were initially sprayed with an $N$. mediterraneum suspension of $4 \times 10^{4}$ spores $/ \mathrm{ml}$ prepared from a culture grown on APDA for 2 weeks. Immediately after spraying with the inoculum, 
six adults for each of the above-described insect species were caged using a nylon mesh ( $1-\mathrm{mm}^{2}$ opening) bag in each of three replicated shoots bearing fruit clusters with 12 to 44 fruit each on 15-year-old trees. Similarly, shoots sprayed with inoculum of $N$. mediterraneum alone were enclosed in similar nylon bags to exclude any hemipteran insects and served as the no-insect control treatments. There was also a treatment with no inoculum and no insects. The numbers of infected fruit, fruit with pycnidia, and fruit exhibiting insect punctures were determined 3 weeks after caging the insects with the fruit clusters. At the end of the experiment, all the insects from the net cages (whether dead or alive) were collected, and the live ones were killed as above and plated on APDA media to determine their contamination with $N$. mediterraneum. The experiment was repeated in the summer of the following year (year 2) using the same insect species and experimental design as in year 1.

Effect of insect density on disease incidence. To determine the effect of insect density on the incidence of disease, four shoots, each bearing healthy clusters (10 to 25 fruit/cluster), were sprayed with a spore suspension of $N$. mediterraneum $\left(1 \times 10^{5}\right.$ spores $\left./ \mathrm{ml}\right)$ and caged with 0 (control $=$ no insect), 1,3 , and 5 adults of $T$. pallidovirens in early August. Because LFB insects were not available for these experiments, $T$. pallidovirens insects were used instead. The incidence of disease and fruit bearing pycnidia of $N$. mediterraneum were evaluated at harvest, which was about 1 month after the initiation of the experiment, by collecting all fruit and examining them under a dissecting microscope $(\times 20)$ or making isolations on APDA from nuts with dubious infections. In total, $45 T$. pallidovirens adults from the above experiments were plated on APDA after surface sterilization in $0.1 \%$ chlorine solution for 3 min to determine whether they were contaminated with $N$. mediterraneum.

Exclusion of insects and birds from fruit clusters in the field. Year 1. To determine whether protection of clusters from insect and bird feeding would affect the incidence of infected fruit by panicle blight, two experiments were conducted. In an experimental pistachio orchard in Solano County, CA, where Botryosphaeria panicle and shoot blight disease was at a light to moderate level, on 15 April 2003 (year 1), 10 shoots bearing three to five fruit clusters (45 to 60 fruit in total) were caged in double-layer nylon mesh (10 strands $/ \mathrm{cm}) \mathrm{se}-$ cured to the fruiting branches with duct tape (not accessible to hemipteran insects and birds). Five of these caged shoots were opened and their fruit was exposed to hemipteran insect feeding on 16 September while the remaining five clusters were kept caged until the end of the experiment (27 September). At the beginning of the experiment, five other control fruit-bearing shoots were marked and kept uncovered (thus accessible to hemipteran insects and birds) continuously during the season until the end of the experiment. All of the fruit from the open, caged, and uncovered clusters on 16 September were harvested by hand on 27 September, brought to the laboratory in an ice chest, and the incidence (\%) of kernel necrosis (a late-season symptom due to feeding by hemipteran insects) and Botryosphaeria fruit blight were assessed. Although most kernel necrosis occurs late in the season and primarily at the fruit stem end ("Achilles heel") and along the suture (Michailides 1989), kernel necrosis and the mold that initiates from it sometimes can develop in other sites of the kernel. Therefore, to determine all possible kernel necrosis, the kernels were split in half, then sliced in 2-mm sections and recorded for kernel mold caused by $N$. mediterraneum and kernel necrosis. This experiment was repeated three times in the same season. Data were analyzed with analysis of variance (ANOVA) and treatment means were separated with the least significant difference (LSD) test.

Year 2. In another orchard in Glenn County, CA with a history of severe Botryosphaeria blight, shoots with clusters were caged before the appearance of any Botryosphaeria blight symptoms on 9 June. In total, 50 nylon mesh $\left(1 \mathrm{~mm}^{2}\right)$ bags $(100 \mathrm{by} 50 \mathrm{~cm}), 2$ bags per each of 25 trees, were used to cover tree branches and protect their fruit clusters from hemipteran insect punctures and bird pecking until commercial harvest. In total, 50 shoots ( 2 per tree) were flagged, kept without a nylon mesh bag covering the clusters, and served as unprotected controls. At harvest (16 September), the cages were opened and all the clusters were harvested as well as the clusters from the unprotected control branches. The fruit clusters were brought to the laboratory and the fruit were evaluated as healthy or blighted. Because there were differences $(P<0.0318)$ among experiments, results of all experiments are shown. These data and data from previous experiments were analyzed with ANOVA and means were separated by Fisher's protected least significant difference test using SAS (release 9.3; SAS Institute Inc.).

Effect of fruit puncturing on infection. To determine whether punctures and pistachio fruit sap contribute to the incidence of infection, the fruit in each of 10 clusters were punctured with a $21 \mathrm{G}$ syringe so that sap was exuded and inoculated immediately by placing a $10-\mu l$ droplet of an $N$. mediterraneum suspension of $8 \times 10^{4}$ conidia $/ \mathrm{ml}$ (treatment 1 ) on the sap. The fruit in 10 additional clusters were first inoculated with the spore suspension and immediately punctured in the center of the inoculum droplet with the same type of syringe as above, so that the exuded sap was mixed with the spore inoculum droplet (treatment 2). All the fruit of another 10 clusters were punctured but were not inoculated and served as a noninoculated control (treatment 3 ), and the fruit in 10 additional clusters were inoculated as above but were not punctured (treatment 4 ). Incidence of disease was recorded at harvest and the experiment was repeated once. Because results from the two experiments were similar $(P=0.1967)$, the combined data were analyzed with ANOVA and treatment means were compared with Fisher's protected LSD test.

Effect of fruit sap on disease development. These experiments were done to simulate insect punctures through the fruit epicarp and determine effects on the incidence of panicle blight disease. Fruit were harvested from an orchard where Botryosphaeria panicle and shoot blight disease was not present and the trees were not sprayed with any fungicides. The fruit were surface sterilized in $0.1 \%$ sodium hypochlorite solution for $2 \mathrm{~min}$ and divided into groups of 30 fruit. Fruit of the first group were punctured with a $21 \mathrm{G} 1$ syringe needle and inoculated with a $10-\mu l$ droplet of a suspension of $N$. mediterraneum at $8 \times 10^{4}$ spores $/ \mathrm{ml}$ added to the sap exuded by puncturing the fruit (treatment 1). A second group of 30 fruit were inoculated first with a $10-\mu l$ droplet of the above spore suspension and immediately punctured through the spore suspension droplet with the 21G1 syringe (treatment 2). A third group of 30 fruit were punctured as above but were not inoculated (noninoculated control, treatment 3 ), and the last group of 30 fruit were inoculated as above but were not punctured (treatment 4). All the fruit were incubated in closed plastic containers with $>95 \%$ relative humidity and infection by $N$. mediterraneum was recorded after 8 days of incubation at $27^{\circ} \mathrm{C}$. Three 10 -fruit replications were used per treatment and the experiment was repeated once.

In another experiment, treatments 1,2 , and 4 were as those described above, and two new treatments were added. Treatment 5 consisted of fruit that were not punctured and inoculated as above but a $25-\mu 1$ droplet of fruit sap obtained from a wounded pistachio fruit was added to them, and treatment 6 consisted of fruit that were not punctured and inoculated as above but the conidial suspension was allowed to dry in a laminar flow hood before adding a $25-\mu 1$ droplet of fruit sap. The fruit were incubated for 8 days and disease was recorded as described above; the experiments were repeated once with fruit from the same orchard. Because results were similar $(P=0.1187)$, they were averaged and analyzed with ANOVA. Fisher's protected LSD test was used to compare treatment differences.

Effect of fruit sap on the pathogen. To determine whether sap produced and exuded from pistachio fruit after sucking insects puncture the fruit had any effect on spore germination of $N$. mediterraneum, a suspension of $N$. mediterraneum of $2 \times 10^{5}$ conidia/ml was prepared from sporulating cultures of the pathogen. Fruit sap was prepared by squeezing crushed, immature pistachio fruit (previously surface sterilized in $0.1 \%$ chlorine solution for $3 \mathrm{~min}$ and kept frozen at $-16^{\circ} \mathrm{C}$ until used) through four layers of cheesecloth. A sterile cover slip was placed on a 50- $\mu$ l drop of the above spore suspension and a 50- $\mu 1$ drop of sterile water was placed in the center of a plate containing $2 \%$ WA. Similarly, a $50-\mu 1$ drop of the spore suspension and 50- $\mu$ l drop of fruit sap were placed in the center of a $2 \%$ WA plate, mixed with a glass rod, and covered with a cover slip as above. There were four replicated plates for each treatment and the plates were incubated at $27^{\circ} \mathrm{C}$. Spore germination was 
observed and recorded hourly for $5 \mathrm{~h}$. The experiment was repeated once.

To determine the effect of fruit sap on growth of $N$. mediterraneum, $5 \mu \mathrm{l}$ of conidial suspension and $5 \mu \mathrm{l}$ of sterile water or $5 \mu \mathrm{l}$ of conidial suspension and $5 \mu \mathrm{l}$ of fruit sap were placed as inoculum in the center of each of four replicated WA plates. Colony diameter was measured after 4,6 , and 9 days of incubation at $27^{\circ} \mathrm{C}$. The experiment was repeated once and, because results were similar $(P=$ 0.2415 ), only results from the first experiment are presented. Mean differences were compared with LSD test.

Effect of number of punctures on infection. To determine whether the number of punctures per fruit affects infection of fruit and disease development, mature 'Kerman' pistachio fruit were collected in midSeptember (year 1), surface sterilized in $0.1 \%$ chlorine solution with Tween 20 at $0.05 \mathrm{ml} /$ liter, washed twice in tap water, air dried, and placed in humid chambers on a plastic mesh. Fruit were then punctured with a transfer needle ( $1 \mathrm{~mm}$ in diameter) by making, 1,3 , or 6 punctures 1 to $2 \mathrm{~mm}$ deep on one side (cheek) of the fruit. Immediately after wounding, fruit were inoculated by spraying to run off a suspension of $N$. mediterraneum at $4 \times 10^{4}$ conidia/ml. The humid chambers with such inoculated fruit were incubated at 27 to $30^{\circ} \mathrm{C}$ and the disease incidence was recorded after 5 and 7 days of incubation. Two 20-fruit replications were used in two repeated experiments. Linear regression was used to study the relationship between the numbers of artificial punctures and the percentage of fruit showing disease symptoms. Because there were differences in the levels of infected fruit between the two experiments, the data of both experiments are presented.

Association of $\mathrm{N}$. mediterraneum with bird-damaged fruit. To determine whether bird injuries are associated with Botryosphaeria fruit blight disease, nuts showing distinct bird damage (i.e., crows, jays, and others, indicated by the uneven rupture of the shell and epicarp of the fruit) were also collected arbitrarily from four commercial orchards each in year 1 and year 2 of this study. Of these orchards, only three had symptoms of Botryosphaeria panicle and shoot blight. Healthy fruit without any bird damage were also collected and served as control fruit not damaged by birds. Bird-damaged and healthy nuts were surface sterilized in a $0.1 \%$ chlorine solution (prepared as above) and three to five fruit were plated in each large $(9 \mathrm{~cm}$ in diameter) petri plate containing APDA. The developing fungi from the plated nuts were recorded after 5 to 6 days of incubation at $27^{\circ} \mathrm{C}$.

\section{Results}

Field observations on a putative association of insect-injured fruit and infection by $N$. mediterraneum. The survey of pistachio orchards during July to August in all years of this study showed single fruit infected, and the infection moved through the peduncle into the main axis (rachis) of the fruit cluster (Fig. 1A and B). Furthermore, infections of fruit by $N$. mediterraneum seemed to surround characteristic wounds oozing sap caused by punctures made by hemipteran insects (Fig. 1C). In fact, the sap drops usually were surrounded by pycnidia of $N$. mediterraneum and infected shriveled tissues of the epicarp. Fruit that showed EP without the presence of any fungal infection were split in half and internal tissues were plated on APDA plates. The incidence of mycelia in the inner surface of shell of intact (nonsplit) fruit was 6 to 100 (average 59\% in 1996), 64 to 100 (79\% in 1997), and 86 to $97 \%$ (average $91 \%$ in 2000) of pistachio fruit with symptoms of EL collected in each year. Of fruit that contained mycelia in the inner surface of the shell, 9 to $100 \%$ (average 53\%) had N. mediterraneum. Sap was present in the center of the injuries made by hemipteran insects in 72 to $100 \%$ of the sampled fruit. Other fungal mycelia present inside the shell were identified as Aspergillus niger, A. ochraceus, A. flavus, Aureobasidium pullulans, Trichothecium roseum, and species of Alternaria, Cladosporium, Epicoccum, Fusarium, Monilia, Mucor, Penicillium, Phomopsis, Rhizopus, and Rhizomucor. Interestingly, a species of Phomopsis was the second most frequently isolated fungus (5.3 to $11.1 \%$ ) from mycelia inside the fruit shell following the incidence of $N$. mediterraneum. No fungi were isolated from the internal tissues of intact (nonsplit) fruit that appeared healthy and without any apparent injury by hemipteran insects or birds.

Mycelia of N. mediterraneum were also found in 69\% (average of all samples) of fruit injured by other species of insect pests of pistachio (i.e., oblique-banded leaf roller).

Isolation of $\boldsymbol{N}$. mediterraneum from insects and insect parts. Of the 45 surface-sterilized Thyanta stinkbugs plated on agar media during both years, 16 of them (36\%) developed colonies of $N$. mediterraneum. In four separate experiments in years 1 and $2, N$. mediterraneum was isolated from 11.8 and 1\% of intact bodies of LFB, 3.4 and $0 \%$ of the stylets (proboscis), 4.8 and $0 \%$ of excrement samples, and 10 and $2 \%$ of insect water washings, respectively. More than $50 \%$ of the spores obtained from insect excrement germinated after $8 \mathrm{~h}$ of incubation on APDA and produced typical $N$. mediterraneum colonies identified after 3 days of incubation at $27^{\circ} \mathrm{C}$.

Disease transmission by hemipteran insects. L. clypealis. Significantly more fruit were infected by $N$. mediterraneum when fruit clusters were sprayed with the pathogen's spore suspension and caged with LFB than when insects were excluded from the inoculum-sprayed clusters. In addition, a low level ( 2 to $3 \%$ ) of infected fruit occurred in clusters not sprayed with fungal inoculum (Fig. 2). Infected fruit developed pycnidia around the puncture wounds made by LFB, and these
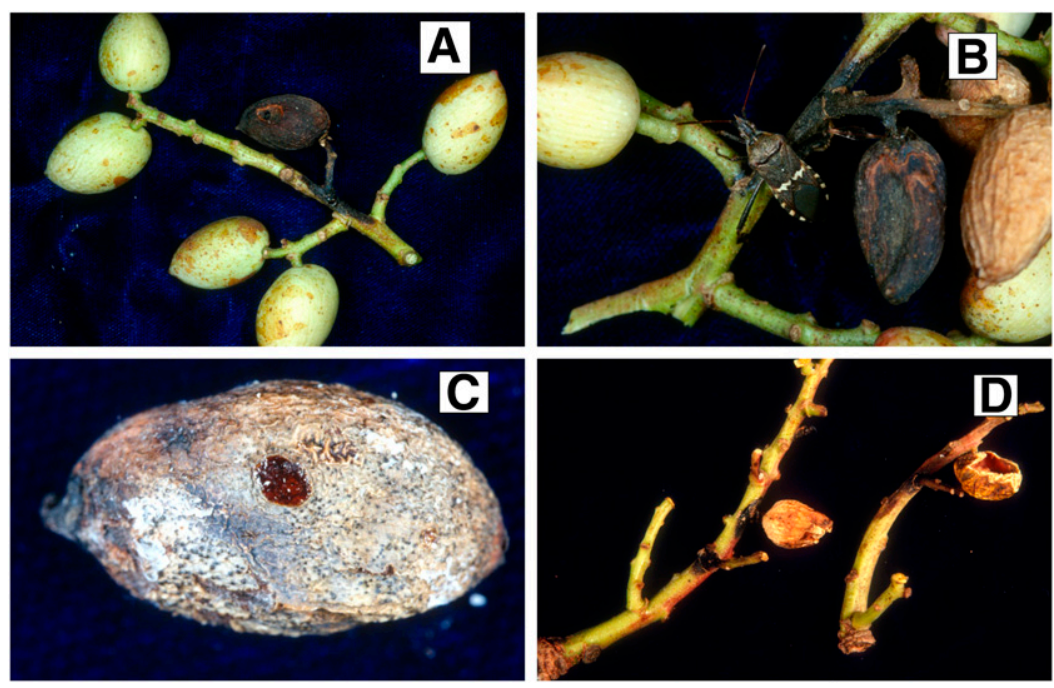

Fig. 1. A and B, Infection of pistachio fruit by Neofusicoccum mediterraneum initiated from insect-punctured fruit and spread into the main rachis of the cluster (note a leaffooted bug [Leptoglossus clypealis] on the rachis of pistachio cluster in B); C, fruit infected by the pathogen and covered with pycnidia surrounding the sap exuded from the insect's injury; D, fruit infections initiated from injuries caused by birds and spread into the main rachis of clusters. 
signs and symptoms resembled those observed in the pistachio orchards. Pycnidia were also formed (however, with no specific aggregation pattern) on fruit that were infected after they had been sprayed with the spores of the pathogen even in the absence of any insects.

Thyanta and Acrosternum. In the second experiment, where Thyanta pallidovirens and Acrosternum hilare were tested, significantly $(P<0.05)$ more disease and pycnidia developed in fruit clusters sprayed with the inoculum and caged with the insects than when fruit were sprayed with inoculum only (Fig. 3). The treatments Thyanta-N. mediterraneum and Acrosternum-N. mediterraneum inoculum resulted in significantly higher incidence of infected fruit than treatments consisting of fruit that were sprayed with inoculum only or nonsprayed. Without the presence of stinkbugs, fruit sprayed with inoculum as well as not sprayed developed very low level of diseases $(<2 \%)$ (Fig. 3).

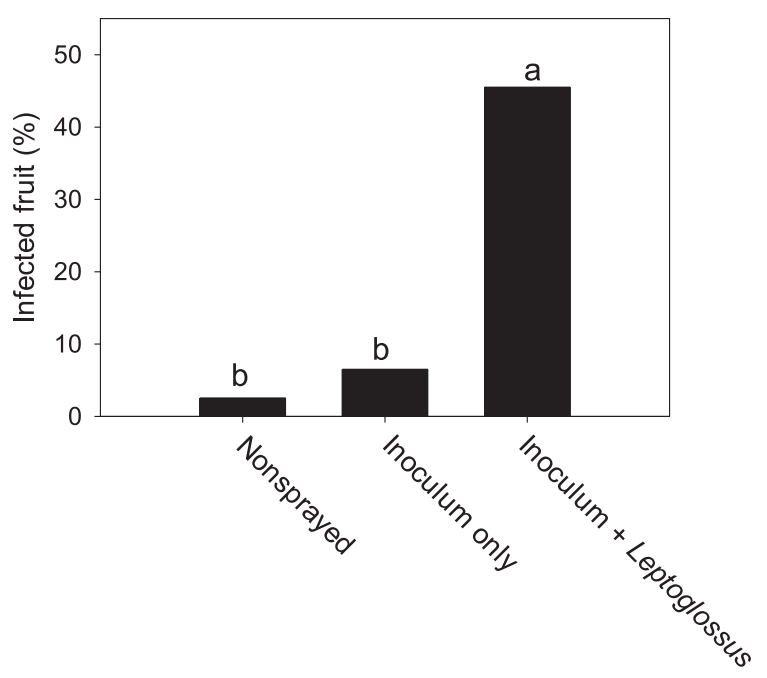

Fig. 2. Incidence of pistachio fruit infected by Neofusicoccum mediterraneum after enclosing fruit clusters with Leptoglossus clypealis (Hemiptera). Bars topped with the same letter are not significantly different according to Fisher's protected least significant difference test. Results represent the average of two repeated experiments.

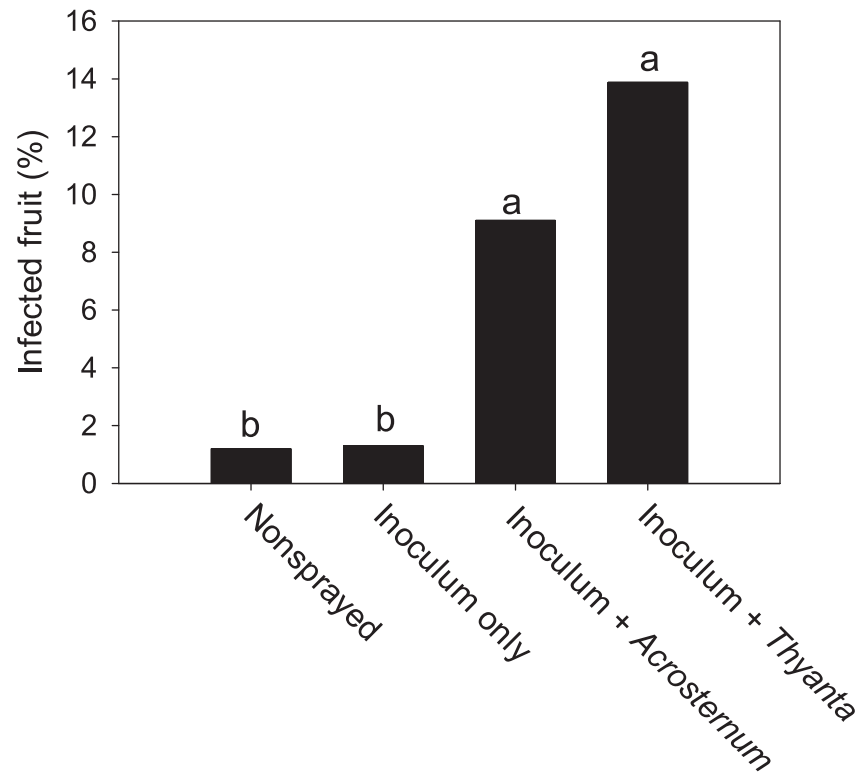

Fig. 3. Incidence of pistachio fruit infected by Neofusicoccum mediterraneum after enclosing fruit clusters with Thyanta pallidovirens and Acrostermum hilare (Hemiptera). Bars topped with the same letter are not significantly different according to a protected Fisher's protected least significant difference test. Results represent the average of two repeated experiments.
Effect of insect density on the disease. The effect of insect density on disease was tested by using adult $T$. pallidovirens insects. Although a very small percentage $(3 \%)$ of fruit were infected by $N$. mediterraneum when only one insect was caged with the fruit clusters, this percentage increased up to 8 and $38 \%$ infected fruit when three and five adult $T$. pallidovirens insects, respectively, were caged with the clusters. The incidence of fruit bearing pycnidia was small, but more fruit developed pycnidia when caged with three or five insects than when caged with one adult insect (Fig. 4). Indeed, none of the fruit caged with one $T$. pallidovirens adult developed any pycnidia in either experiment.

Furthermore, when the fruit were categorized based on the number of insect punctures and evaluated for disease, the incidence of infected fruit and the incidence of fruit bearing pycnidia were positively related with the density of insect punctures or wounds on pistachio epicarp (Fig. 5). Where $y$ is the incidence of infected fruit or fruit with pycnidia and $x$ is the number of punctures per pistachio caused by T. pallidovirens adults, $R^{2}=0.56$ and 0.38 , significant at $P=0.012$ and 0.056 , respectively (Fig. 5).

Exclusion of insects from fruit clusters in the field. In the Solano County orchard, fruit not protected (noncaged) with a net bag had $45.4 \%$ incidence of kernel necrosis, which represents damage of the kernel due to feeding by hemipteran, and showed 3\% infected by panicle blight (Table 1). Fruit protected from insects with a net mesh for various durations of time had significantly $(P=0.042)$ lower kernel necrosis (23 to 30\%) whereas the fruit that were protected the longest (15 April to 27 September at harvest) had the lowest incidence of kernel necrosis (17.6\%) and none of the fruit were infected. Similar results were obtained in year 2, except the noncaged fruit developed $48.5 \%$ kernel necrosis and only $0.5 \%$ were infected (Table 1).

In the Glenn County pistachio orchard, clusters protected from hemipteran punctures and by injuries from bird feeding until harvest had $30 \%$ of fruit infected by panicle and shoot blight disease while almost twice as much disease (59\% of fruit infected) developed in the clusters that were not caged with the net bags $(P=0.01$, data not shown).

Effect of fruit puncturing on infection. In the laboratory inoculations, incidence of infection of fruit ranged from 97 to $100 \%$ for both fruit inoculated first and then punctured and fruit punctured first and then inoculated (treatments 1 and 2, respectively; Fig. 6A). Fruit that were punctured and not inoculated (treatment

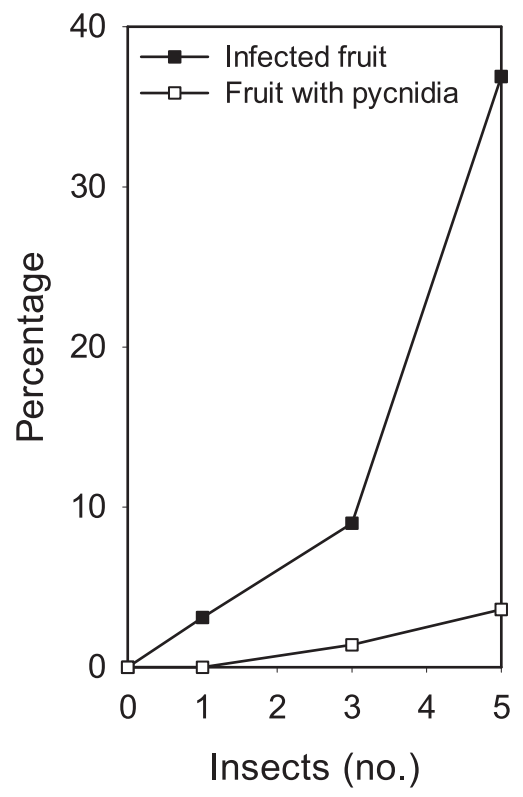

Fig. 4. Effect of various numbers of Thyanta pallidovirens adults caged with pistachio fruit clusters sprayed with a conidial suspension of Neofusicoccum mediterraneum on infection and production of pycnidia. 
3 ) did not develop any disease whereas $45 \%$ of fruit that were not punctured and inoculated (treatment 4) were infected (Fig. 6A). Disease levels in the field were lower in general than those in the laboratory (Fig. 6B) but conclusions were similar. There was no difference in disease incidence on fruit (18 and 25\%) that were punctured first and then inoculated and those that were inoculated first and then punctured. Disease developed on only $2 \%$ of the fruit that were punctured but not inoculated (control treatment 3 ). No infections were observed on fruit that were inoculated but not punctured (treatment 4), suggesting that the inoculum dried quickly in the field (Fig. 6B).

Effect of fruit sap on disease development. The addition of fruit sap onto fruit that were inoculated but not punctured with a needle resulted in a significant increase of infection by $N$. mediterraneum (treatment 5; Fig. 7A and B) in comparison with the infection of fruit that were inoculated, not punctured, and sap was not added (treatment 4; Fig. 7A). Adding sap to the fruit punctured before or after inoculation did not affect the levels of decay (treatments 1 and 2; Fig. 7A and B). When fruit were inoculated with a very small droplet of spore suspension of $N$. mediterraneum and allowed to dry in a laminar flow hood before adding the fruit sap droplet, they were not infected (treatment 6; Fig. 7B).

Effect of fruit sap on the pathogen. Adding fruit sap to the spore suspension increased the spore germination rate of $N$. mediterraneum. For example, spore germination was 3,51, 62, and $78 \%$ in water alone and 3, 58, 84, and 96\% after adding fruit sap and incubating for 1,2,3, and $5 \mathrm{~h}$ at $27^{\circ} \mathrm{C}$, respectively. Differences in spore germination were significant $(P<0.05)$ for the 3- and 5-h incubations. The growth of $N$. mediterraneum was significantly greater after the addition of fruit sap than without the sap but the growth rate over time remained the same (Fig. 8).

Effect of fruit punctures on infection. Increasing the number of artificial punctures resulted again in higher levels of infected fruit and fruit bearing pycnidia (Fig. 9, experiments 1 and 2A). Wounds were not necessary for disease symptoms. Although the disease was significantly lower on fruit that were not wounded and inoculated than on fruit wounded (regardless of the number of wounds) and inoculated after 5 days of incubation, this difference was diminished by the seventh day of incubation (Fig. 9, experiment 2).

Association of $\boldsymbol{N}$. mediterraneum with bird-damaged fruit. $N$. mediterraneum was isolated from 13 to $58 \%$ (average 34\%) of fruit damaged by birds and collected from three orchards where panicle and shoot blight was present and from 0 to $10 \%$ (average $4.5 \%$ ) of fruit collected from four orchards where Botryosphaeria panicle and shoot blight symptoms were not present at the time of fruit collection. Other filamentous fungi isolated from bird-injured fruit included Alternaria

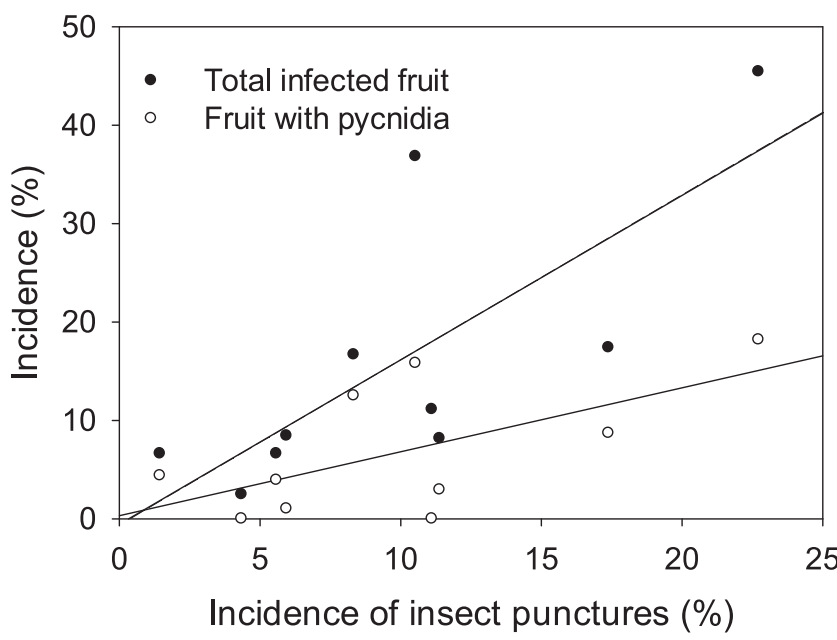

Fig. 5. Relationship between incidence of the density of insect punctures of pistachio fruit and - infected fruit $\left[y=-0.54+1.67 x ; R^{2}=0.56, P<0.01\right.$ ) and $\bigcirc$, fruit bearing pycnidia $\left[y=0.32+0.65 x ; R^{2}=0.38, P<0.05\right.$ ) produced by Neofusicoccum mediterraneum. alternata, Aspergillus niger, A. flavus, A. parasiticus, A. ochraceus, A. terreus, Botrytis cinerea, Choanophora cucurbitarum, Epicoccum purpurescans, Fusarium dimerum, Rhizopus stolonifer, Trichothecium roseum, and species of Cladosporium, Curvularia, Fusarium, Mucor, Neurospora, Nigrospora, Penicillium, Phomopsis, and Stemphylium. Nonfilamentous fungi included Aureobasidium pullulans, Eremothycium coryli, and other rare and unidentified yeasts.

\section{Discussion}

The high frequency of isolating $N$. mediterraneum from the kernels or the inner shell surface of nonsplit, immature pistachio fruit showing symptoms of EL, which is only in response to feeding punctures by hemipteran insect (Bolkan et al. 1984; Rice et al. 1985), was the first observation of a putative association of hemipteran insects and panicle and shoot blight of pistachio. There are two possibilities that can explain this association: (i) either the hemipteran insects create wounds and, thus, facilitate latent infection by propagules already present on the fruit surface or (ii) it is likely that these insects can pick up the sticky conidia of $N$. mediterraneum as they walk on the plant surface and passively spread them among the pistachio fruit in their attempts to find a suitable site for feeding. This association of hemipteran insects and the Botryosphaeria panicle and shoot blight disease is also supported by the fact that, in pistachio orchards, the first symptom of the disease commonly is single fruit showing disease lesions starting from punctures of hemipteran insects. Furthermore, isolation of $N$. mediterraneum from the insect bodies and stylets supports the contention that contamination of these insects with propagules of the pathogen can occur in the orchard. Although it is difficult to accurately explain the large differences between the surveyed years in the incidence of $N$. mediterraneum mycelia in the fruit cavity, it is a fact that the damage by hemipteran insects and the spread of the pathogen's inoculum can vary from year to year.

The mouse-gray, fluffy mycelia of $N$. mediterraneum were found at high frequencies inside the shell of pistachio fruit by early August and pycnidia of the pathogen formed around the insect's punctures by late August. Additionally, isolation of a number of other fungal species (common fungi found on the surface of pistachio; Chen et al. 2001) from mycelia developed in the inner surface of insectinjured, nonsplit fruit but not from uninjured fruit, another indication that hemipteran insects facilitated the spread of these fungi in the inner cavity of pistachio fruit by either creating a puncture wound, inserting fungal propagules within the fruit cavity, or both. However, among the fungi isolated from the kernel of pistachio fruit, only $N$. mediterraneum and an occasional Phomopsis sp. grew through the peduncle, thus reaching the panicle rachis and causing panicle blight. A Phomopsis sp. was also reported to cause shoot blight of

Table 1. Effect of caging pistachio fruit clusters on Botryosphaeria panicle and shoot blight disease in a Solano County orchardy

\begin{tabular}{|c|c|c|}
\hline Treatment $^{\mathrm{z}}$ & $\begin{array}{c}\text { Kernel } \\
\text { necrosis }(\%)\end{array}$ & $\begin{array}{c}\text { Botryosphaeria } \\
\text { decay }(\%)\end{array}$ \\
\hline \multicolumn{3}{|l|}{ Experiment 1} \\
\hline Noncaged & $45.4 \mathrm{a}$ & $3.0 \mathrm{a}$ \\
\hline $\begin{array}{l}\text { Caged } 15 \text { April, uncovered } \\
16 \text { September }\end{array}$ & $30.0 \mathrm{~b}$ & $2.4 \mathrm{ab}$ \\
\hline $\begin{array}{l}\text { Caged } 15 \text { April, uncovered } \\
27 \text { September }\end{array}$ & $17.6 \mathrm{c}$ & $0.0 \mathrm{~b}$ \\
\hline \multicolumn{3}{|l|}{ Experiment 2} \\
\hline Noncaged & $48.5 \mathrm{a}$ & $0.5 \mathrm{a}$ \\
\hline $\begin{array}{l}\text { Caged } 9 \text { June, uncovered } \\
16 \text { September }\end{array}$ & $23.1 \mathrm{~b}$ & $0.0 \mathrm{a}$ \\
\hline \multicolumn{3}{|c|}{$\begin{array}{l}\text { y Values are the average of five replicated shoots from three trees. For each } \\
\text { experiment in each column, numbers followed by the same letters are not } \\
\text { significantly different }(P<0.05) \text { according to Fisher's protected least signif- } \\
\text { icant difference test at } P=0.05 \text {. }\end{array}$} \\
\hline \multicolumn{3}{|c|}{$\begin{array}{l}\mathrm{z} \text { All covered and uncovered clusters and shoots without any bags were eval- } \\
\text { uated for kernel necrosis and Botryosphaeria blight after harvest on } 27 \\
\text { September. }\end{array}$} \\
\hline
\end{tabular}


pistachio (Michailides 2002). Furthermore, among the fungi isolated, some can cause serious diseases on pistachio (i.e., stigmatomycosis, Alternaria late blight, kernel decay, and, very occasionally, contamination with mycotoxins). However, none of these fungi will result in cankered or blighted panicles as Botryosphaeria panicle and shoot blight will do.

Hemipteran insects are major pests of nut crops. In some years, pistachio can suffer substantial losses (Bolkan et al. 1984; Michailides et al. 1987; Rice et al. 1985), and growers treat their crops yearly with insecticides to reduce this damage. At least three large hemipteran insects tested in this study resulted in increased levels of disease in inoculated fruit as compared with the disease developed on inoculated fruit in the absence of these insects (Figs. 2 and 3). Although small hemipteran insects can also be serious pests of pistachio early during the development and before the lignification of the fruit shell (Michailides et al. 1987), and may have a similar association with the panicle and shoot blight disease of pistachio, only large hemipteran insects were investigated in this study, because they are believed to be more damaging in general than the small insects. The large insects can puncture pistachio fruit even after the lignification of the shell which, under California conditions, occurs in the last week of May (Michailides et al. 1988). Close to harvest, even the large hemipteran insects are unable to puncture the fruit through the shell but they are able to sense a softer area close to the fruit peduncle and are able to insert their stylet and reach the kernel through that area (the "Achilles heel" of pistachio; Michailides 1989). Depending on the developmental stage of mycelial infection of fruit, in several instances, mycelia of $N$. mediterraneum were present around the stem end area (T. J. Michailides, unpublished).

Increasing the number of Thyanta pallidovirens insects caged with the pistachio clusters resulted in higher incidence of disease and more fruit with pycnidia. When more hemipteran insects feed on a given number of pistachio fruit rather than fewer insects, these fruit are expected to suffer more feeding punctures. The increased disease incidence and fruit bearing pycnidia with the high density of insects can be explained easily by the increased number of punctures per fruit that result in an increased chance for the fruit infection (Figs. 4 and $5)$. There was a positive and significant linear correlation between the incidence of punctures and infection by $N$. mediterraneum and the incidence of fruit that developed pycnidia. When pistachio clusters were protected from insect damage all the time until harvest, disease did not develop; when the fruit were not protected at all from insect injuries or protected for only part of the season, disease developed to the highest and intermediate levels, respectively (Table 1). However, in the Glenn orchard, which is located in the northern part of the state where pistachio fruit are grown, the incidence of disease

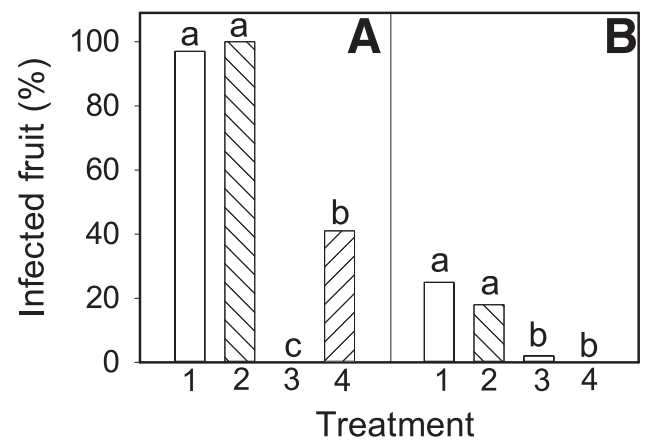

Fig. 6. Effect of mechanical wounding of pistachio on infection of fruit inoculated with Neofusicoccum mediterraneum. A, In the laboratory and B, in the field, treatment 1 = fruit were first punctured with a $21 \mathrm{G} 1$ syringe and then inoculated with conidia of $N$. mediterraneum per puncture, treatment $2=$ fruit were inoculated first as above and then punctured, treatment $3=$ fruit were punctured but not inoculated, and treatment $4=$ fruit were inoculated as above but not punctured (10 replicated clusters per treatment). Different letters above bars indicate significant $(P<0.05)$ differences among treatments using Fisher's protected least significant difference test. was high even in caged clusters. This orchard has a lot of pathogen inoculum and gets more rainfall than the Solano orchard does. The high level of disease can be explained by the latent infections due to rains, leading to high levels of fruit blight at harvest (Michailides and Morgan 2004).

Hemipteran insects are still considered a major pest, with the potential for contributing to high damage of pistachio in California. Controlling these insects in pistachio orchards will reduce not only the EL (which represents the direct damage of fruit by these insects) but also the spread and level of panicle and shoot blight. There are now several registered insecticides that growers routinely use to reduce damage by hemipteran insects.

The pathogen causing Botryosphaeria panicle and shoot blight does not require wounds for infection because it can infect green fruit, shoots, and leaves and cause latent infections (Michailides 1991; Michailides and Morgan 2004). However, wounding certainly enhances the fruit infection process, resulting in a higher infection level of wounded and inoculated fruit than in inoculated fruit without any wounding (Figs. 6 and 7). Wounding increases the incidence of infection, as is the case when hemipteran insects are caged with healthy pistachio clusters. In addition, the exuded fruit sap when hemipteran insects puncture the fruit may act directly on either the pathogen's propagules that may be present on the fruit surface or those brought onto the fruit by the insect. Either the actual puncture (wound) or the exuded sap can favor spore germination and growth of $N$. mediterraneum by providing needed moisture and nutrients. However, if the droplet containing the pathogen's spores dried quickly or the quantity of the exuded sap was very small and dried before spores were able to germinate, the rate of infection could be reduced (Fig. 7B, treatment 6). The quick appearance of symptoms from fruit infections after wounding (puncturing the fruit with a needle) can
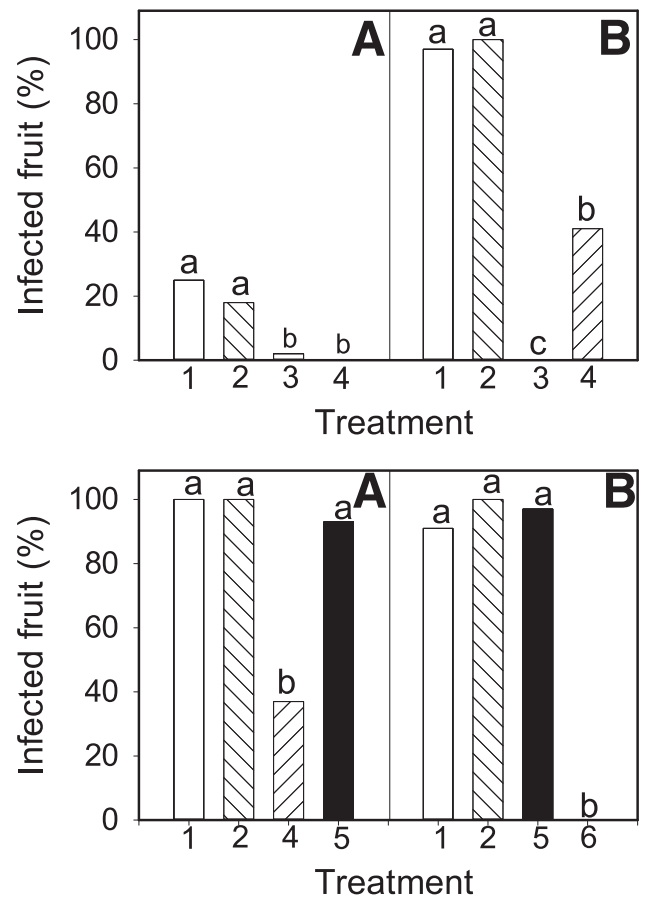

Fig. 7. Effect of wounding and addition of fruit sap on infection of pistachio by Neofusicoccum mediterraneum. A, Experiment 1: treatment 1 = fruit were first punctured with a $21 \mathrm{G} 1$ syringe and then inoculated with conidia of $N$. mediterraneum per puncture, treatment 2 = fruit were inoculated first as above and then punctured, treatment $4=$ fruit were inoculated as above but not punctured, and treatment $5=$ fruit were inoculated as above but not punctured and a drop of $25 \mu \mathrm{l}$ of fruit sap was added (10 replicated clusters per treatment). B, Experiment 2: treatments 1, 2 , and 5 were as described in A; treatment $6=$ fruit inoculated and not punctured but inoculum was allowed to dry before adding the $25-\mu$ l drop of fruit sap (three replications of 10 fruit each per treatment). Different letters above bars indicate significant $(P<0.05)$ differences among treatments using Fisher's protected least significant difference test. Each experiment was repeated once. 
explain why the first disease symptoms in an orchard occurred on fruit injured by hemipteran insects.

This study showed that the sap alone increased disease levels equivalent to the effect of wounding. Because $N$. mediterraneum infects nonwounded tissues, it is mainly the contact of sap and the nutrients in it with the pathogen's spores that contribute to an acceleration of the disease and not the breaking of the integrity of the fruit tissues. For instance, there were no differences between disease levels of fruit inoculated and wounded, or wounded and inoculated, or inoculated and supplied with a small drop of sap but not wounded (Figs. 6 and 7). (Pistachio fruit sometimes exude sap without wounding, such as when they are subjected to direct excess sun heat.) Apparently, the pistachio sap on its own has enough nutrients to enhance spore germination and increase the growth of $N$. mediterraneum after germination, as shown in this study (Fig. 8). Therefore, when the sap comes in direct contact with the spores, it enhances the pathogen's infection process.

Hemipteran insects migrate among various hosts, depending on the availability of feeding sources. For instance, large hemipteran insects (i.e., LFB) frequently can be found overwintering on incense cedar trees, citrus, pomegranate, sunflower, safflower, and ornamental pistachio (T. J. Michailides, personal observations). It seems that these insects also aggregate in specific hosts (i.e., citrus and pomegranate), which frequently are planted next to pistachio trees in the central valley of California. Pistachio is considered a preferred host for large hemipteran insects, causing significant EL damage. The high association of $N$. mediterraneum with pistachio fruit injured by insects is an indication that these insects could passively pick up propagules of $N$. mediterraneum and carry them to pistachio fruit. Propagules of $N$. mediterraneum were recovered from washings of LFB bodies, or by direct plating on media, body parts, and stylets of this insect. L. clypealis is a large and hairy insect that is considered to be a major pest of both pistachio and almond (Daane et al. 2000). Therefore, these hemipteran insects, if left unmanaged, may play an important role in the epidemiology and spread of panicle and shoot blight of pistachio and, in some instances, they may introduce the pathogen to new orchards. These findings are supported by another study in which it was shown that $N$. mediterraneum could persist on this insect longer than on hairless hemipteran insects (Steffan et al. 2000). Apparently, the hairy body and legs of these insects are well suited for trapping and carrying $N$. mediterraneum spores.

Several species of birds cause damage to pistachio (Salmon et al. 1986). In this study, up to $58 \%$ of bird-injured fruit (average $34 \%$ ) had Botryosphaeria blight. Although this is not direct evidence that birds transmit $N$. mediterraneum, the high association of the pathogen with bird-injured fruit is worth noting. Birds create wounds on the pistachio fruit by pecking and tearing the hull and shell tissues, and the wounds provide entry points for infection by the pathogen. Although $N$. mediterraneum can cause infection of nonwounded fruit, wounds as well as nutrients from fruit facilitate infection.

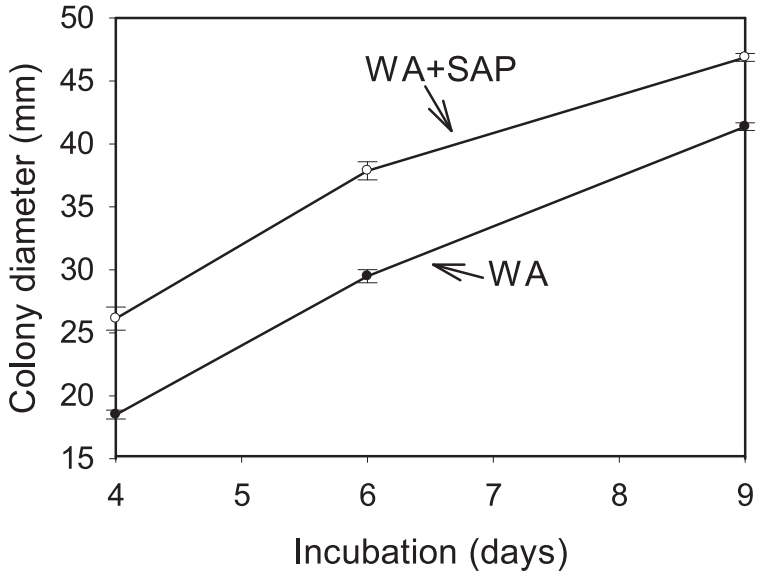

Fig. 8. Effect of fruit sap (SAP) on growth of Neofusicoccum mediterraneum in petri plates containing water agar (WA) after 9 days of incubation at $27^{\circ} \mathrm{C}$.
Therefore, hemipteran insects and birds could contribute to both, bringing the inoculum to pistachio fruit and, at the same time, creating wounds that exude sap, all of which could favor fruit infection.

In addition to $N$. mediterraneum, a number of fungal species were isolated from bird-injured fruit. The species diversity of these fungi was wider for bird-injured fruit than insect-punctured fruit. This might be because birds may be contaminated more easily than the hemipteran insects by propagules of fungi or by visiting a greater number of different hosts (fresh fruit and nuts) than insects. In contrast, contamination of hemipteran insects by fungal propagules seems not to be as easy, especially of the hairless hemipteran insects such as $T$. pallidovirens, Acrosternum hilare, and others. Although at a very low incidence, contamination and eventually infection of fruit by Aspergillus flavus and A. parasiticus is extremely problematic because these fungi produce aflatoxins that contaminate pistachio (Doster and Michailides 1994; Sommer et al. 1986; Thomson and Mehdy 1978). Another reason for the increased fungal diversity of bird-injured fruit could be that these injuries are more severe and larger than the "needle" type injury made by hemipteran insects, thus exposing more injured surface to the environment. When pistachio clusters were protected from punctures of hemipteran insects and bird pecks after covering them with a nylon mesh, they showed less kernel necrosis and as much as $50 \%$ reduction in panicle and shoot blight disease, suggesting that control of these insects and birds in an orchard should aid in the management of panicle and shoot blight of pistachio.

The species $N$. mediterraneum produces numerous pycnidia under the epidermal layers of the fruit epicarp, and infected clusters often are retained on the tree even after mechanical shaking to harvest
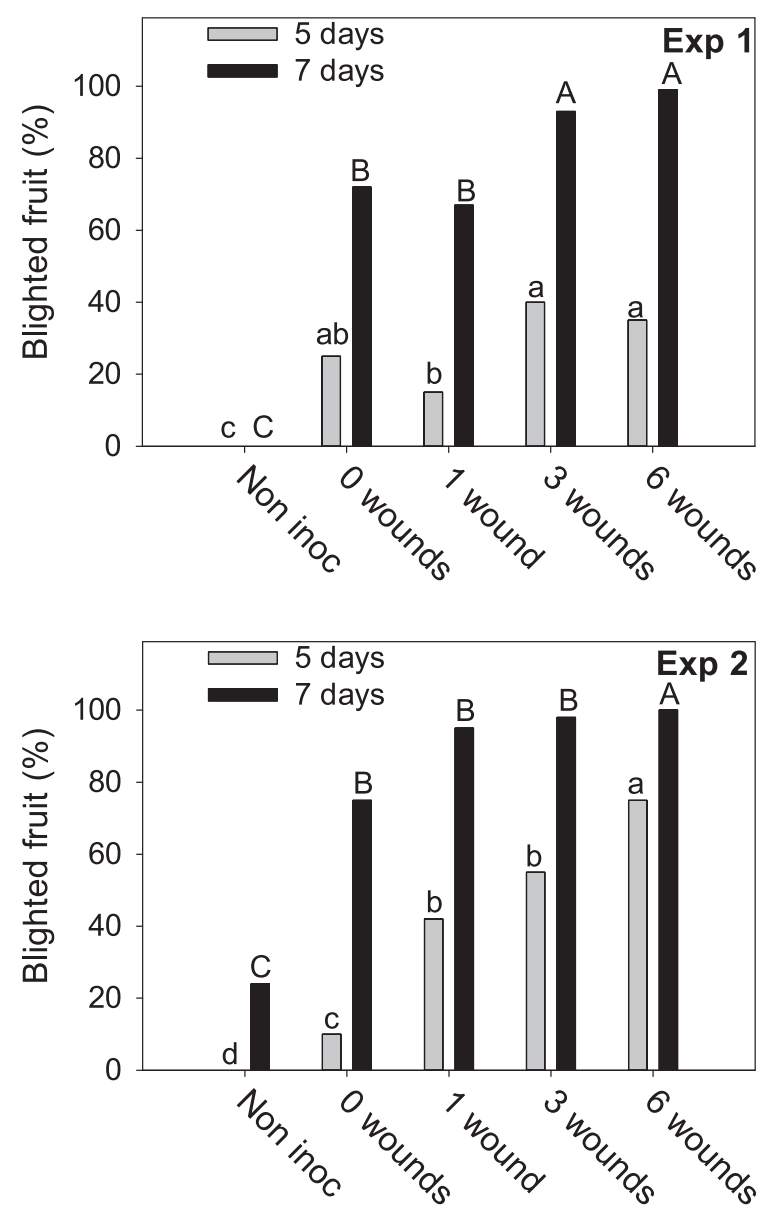

Fig. 9. Effect of the number of artificial wounds (punctures) of pistachio fruit on infection by Neofusicoccum mediterraneum after inoculation and incubation for 5 and 7 days at $27^{\circ} \mathrm{C}$ in two experiments. Different letters above bars indicate significant $(P<0.05)$ differences among treatments using Fisher's protected least significant difference test. 
the crop (Michailides 1991). Birds often feed on these fruit ("mummies") during fall, winter, and early spring, when availability of food sources is limited in the fields. The conidia of the pathogen are mainly spread by water; thus, it is expected that winter rains will make pycnidiospores ooze from pycnidia. Therefore, it is possible that, when birds feed on infected fruit, they may become contaminated with the pycnidiospores of the pathogen. More research is necessary to determine the possible involvement of birds in spreading $N$. mediterraneum and other Botryosphaeriaceae fungi in pistachio orchards, particularly because species of Botryosphaeriaceae can now cause a severe canker and blight disease of walnut (Chen et al. 2014a) and are isolated frequently from other hosts such as blackberry, elderberry, and hackberry, in California (Michailides and Morgan 2004). Birds frequently visit these plants to eat their fruit, and many of these plants can be found next to pistachio orchards and along roads and creeks next to the orchards.

This is the first experimental evidence that at least three large hemipteran pests, such as those used in this study, can play an important role in the infection of pistachio fruit by $N$. mediterraneum. Fungal mycelia, frequently of $N$. mediterraneum, were initiated from stylet punctures in the inner surface of closed pistachio shells. Chitzanidis (1994) reported that infections for Botryosphaeria blight of 'Aegina' pistachio fruit in Greece (known there as Camarosporium blight) often started through wounds caused by a thysanopteran insect pest (Palumbina guerinii). Hemipteran insects have been shown also to transmit tree diseases caused by yeasts, such as stigmatomycosis of pistachio fruit caused by E. coryli (Ershard and Barkordary 1976) and similar diseases on other fruit (Miyao et al. 2000; Shivas et al. 2005).

In conclusion, Botryosphaeria panicle and shoot blight is a widespread disease throughout the pistachio-growing regions in the central valley of California. The pathogen was associated closely with fruit showing punctures and EL caused by hemipteran insects and bird damage. At least three of these hemipteran insects-LFB, Thyanta, and Acrosternum adults-were able to transmit the pathogen and cause significant disease levels, particularly late in the season. In addition to bringing propagules of the pathogen to the host, these hemipteran insects create injuries that ooze fruit sap, all of which favor infection and disease development.

\section{Acknowledgments}

We thank K. Daane (entomologist, University of California, Berkeley) for suggestions on rearing Hemiptera insects in the laboratory, J. Moral for reviewing the manuscript, all the pistachio growers who allowed sampling of their orchards, and the California Pistachio Research Board for financial support of this project.

\section{Literature Cited}

Adesemoye, A. O., Mayorquin, J. S., Wang, D. H., Twizeyimana, M., Lynch, S. C., and Eskalen, A. 2014. Identification of species of Botryosphaeriaceae causing bot gummosis in citrus in California. Plant Dis. 98:55-61

Bolkan, H. A., Ogawa, J. M., Rice, R., Bostok, R. M., and Crane, J. C. 1984. Leaffooted bug implicated in pistachio epicarp lesion. Calif. Agric. 38:16-17.

Brooks, F. E., and Ferrin, D. M. 1994. Branch dieback of southern California chaparral vegetation caused by Botryosphaeria dothidea. Phytopathology 84 : 78-83.

Carter, W. 1973. Insects in Relation to Plant Disease. John Wiley and Sons, New York.

Chen, S. F., Morgan, D. P., Hasey, J. K., Anderson, K., and Michailides, T. J. 2014a. Phylogeny, morphology, distribution, and pathogenicity of Botryosphaeriaceae from English walnut in California. Plant Dis. 98:636-652.

Chen, S. F., Morgan, D. P., and Michailides, T. J. 2014b. Botryosphaeriaceae and Diaporthaceae associated with panicle and shoot blight of pistachio in California, USA. Fungal Biol. 67:157-179.

Chen, W. Q., Ntahimpera, N., Morgan, D. P., and Michailides, T. J. 2001. Mycoflora of Pistacia vera in the central Valley, California. Mycotaxon 83:147-158.

Chitzanidis, A. 1994. Pistachio diseases in Greece. Acta Hortic. 419:345-348.

Daane, K. M., Steffan, S. A., Yokota, G. Y., and Michailides, T. J. 2000. Biological investigations of Hemiptera pests to improve control and reduce the spread of the fungus Botryosphaeria dothidea. Pages 19-20 in: Calif. Pistachio Ind. Annu. Rep. Crop Year 1999-2000. Fresno, CA.

Daugherty, D. M. 1967. Pentatomidae as vectors of yeast-spot disease of soybeans. J. Econ. Entomol. 60:147-152.

Doster, M. A., and Michailides, T. J. 1994. Aspergillus molds and aflatoxins in pistachio fruit in California. Phytopathology 84:583-590.
Ershard, D., and Barkordary, M. 1976. Investigations on stigmatomycosis (massu disease) of pistachio. Iran. J. Plant Pathol. 12:17-23.

Inderbitzin, P., Bostock, R. M., Trouillas, F. P., and Michailides, T. J. 2010. A six locus phylogeny reveals high species diversity in Botryosphaeriaceae from California almond. Mycologia 102:1350-1368.

Kolařík, M., Freeland, E., Utley, C., and Tisserat, N. 2011. Geosmithia morbid asp. nov., a new phytopathogenic species living in symbiosis with the walnut twig beetle (Pityophthorus juglandis) on Juglans in USA. Mycologia 103:325-332.

McDonald, V., and Eskalen, A. 2011. Botryosphaeriaceae species associated with avocado branch cankers in California. Plant Dis. 95:1465-1473.

Michailides, T. J. 1989. The "Achilles heel" of pistachio fruit. Calif. Agric. 43: $10-11$

Michailides, T. J. 1991. Pathogenicity, distribution, sources of inoculum, and infection courts of Botryosphaeria dothidea on pistachio. Phytopathology 81: 566-573.

Michailides, T. J. 2002. Phomopsis blight. Page 69 in: Compendium of Nut Crop Diseases in Temperate Zones. B. L. Teviotdale, T. J. Michailides, and J. Pscheidt, eds. American Phytopathological Society Press, St. Paul, MN.

Michailides, T. J., and Morgan, D. P. 1990. Etiology and transmission of stigmatomycosis disease of pistachio in California. (Abstr.) Phytopathology 80:973

Michailides, T. J., and Morgan, D. P. 2004. Panicle and shoot blight of pistachio: A major threat to the California pistachio industry. Online publication. APSnet Featured Article. doi:10.1094/APSnetFeature-2004-0104

Michailides, T. J., and Morgan, D. P. 2010. Diseases of tree nut crops caused by Botryosphaeriaceae fungi. CAPCA Adviser 8(5):34-35, 38, and 40.

Michailides, T. J., Morgan, D. P., and Felts, D. 1997. Spread of Botryosphaeria dothidea in central California pistachio orchards. Acta Hortic. 470:582-591.

Michailides, T. J., Morgan, D. P., Felts, D., and Chitzanidis, A. 1998. Disease monitoring and prediction of Botryosphaeria blight in California pistachio orchards. Pages 72-76 in: Calif. Pistachio Ind. Annu. Rep. Crop Year 1997 1998. Fresno, CA.

Michailides, T. J., Rice, R. E., and Ogawa, J. M. 1987. Succession and significance of several hemipteran insects attacking a pistachio orchard. J. Econ. Entomol. 80:398-406.

Michailides, T. J., Rice, R. E., and Ogawa, J. M. 1988. Sites of epicarp lesion (EL) and kernel necrosis (KN) in relationship to symptom and phenology of pistachio fruit. J. Econ. Entomol. 81:1152-1154.

Miyao, G. M., Davis, R. M., and Phaff, H. J. 2000. Outbreak of Eremothecium coryli fruit rot of tomato in California. Plant Dis. 84:594

Moral, J., Muñoz-Díez, C., González, N., Trapero, A., and Michailides, T. J. 2010 Characterization and pathogenicity of Botryosphaeriaceae species collected from olive and other hosts in Spain and California. Phytopathology 100:13401351.

Moral, J., Pérez-Rodríguez, M., Michailides, T. J., and Trapero, A. 2015. First report of the teleomorph of Neofusicoccum mediterraneum, a pathogen of olive. (Abstr.) Phytopathology 105:S4.97.

Rice, R. E., Bentley, W. J., and Beede, R. H. 1988. Insect and Mite Pests of Pistachios in California. Univ. Calif. Div. Agric. Nat. Resour. Publ. 21452. Oakland.

Rice, R. E., Michailides, T. J., Jones, R. A., and Ogawa, J. M. 1986. Biology and control of insects causing epicarp lesion and kernel necrosis in pistachios. Pages 64-68 in: Annu. Rep. Crop Year 1985/86, Calif. Pistachio Ind. Fresno.

Rice, R. E., Uyemoto, J. K., Ogawa, J. M., and Pemberton, W. M. 1985. New findings on pistachio problems. Calif. Agric. 39:15-18.

Salmon, T. P., Crabb, A. C., and Marsh, R. E. 1986. Bird damage to pistachio. Calif. Agric. 40:5-8.

Shivas, R. G., Smith, M. W., Marney, T. S., Newman, T. K., Hammelswang, D. L., Cooke, A. W., Pegg, K. G., and Pascoe, I. G. 2005. First report of Nematospora coryli in Australia and its association with dry rot of Citrus. Australas. Plant Pathol. 34:99-101.

Sommer, N. F., Buchanan, J. R., and Fortlage, R. J. 1986. Relation of early splitting and tattering of pistachio fruit to aflatoxin in the orchard. Phytopathology 76: 692-694.

Somonet, J. 1955. Note relative aux Hémiptèeres capturés sur les champignons Mitt. Schweiz. Entomol. Ges. 28:111-114.

Steffan, S. A., Daane, K. M., Yokota, G. Y., Michailides, T. J., and Holtz, B. A. 2000. Hemipteran pests of pistachio and their relationship with Botryosphaeria dothidea. KAC Plant Prot. Q. 10:3-7.

Thomson, S. V., and Mehdy, M. C. 1978. Occurrence of Aspergillus flavus in pistachio fruit prior to harvest. Phytopathology 68:1112-1114.

Tisserat, N., Cranshaw, W., Leatherman, D., Utley, C., and Alexander, K. 2009. Black walnut mortality in Colorado caused by the walnut twig beetle and thousand canker disease. Online publication. Plant Health Prog. doi:10.1094/PHP2009-0811-01-RS

Wheeler, A. G., Jr. 2001. Prospects for improved rearing techniques. Page 273 in Biology of Plant Bugs (Hemiptera: Miridae) Pests, Predators, Opportunities. Cornell Series in Arthropod Biology, 1st ed. Cornell University Press, Ithaca, NY.

Worrall, J. J., Correll, J. C., and McCain, A. H. 1986. Pathogenicity and teleomorphanamorph connection of Botryosphaeria dothidea on Sequoiadendron giganteum and Sequoia sempervirens. Plant Dis. 70:757-759. 